\title{
La escasa representación turística de los ámbitos no urbanos. Una comparación de fuentes impresas e imágenes de Instagram.
}

\author{
Daniel Paül i Agusti*
}

Universitat de Lleida (España)

\begin{abstract}
Resumen: La imagen de un espacio resulta fundamental para la atracción de los turistas. Ahora bien, no todos los espacios disponen de una imagen con el mismo grado de reconocimiento. En el presente artículo se analiza el papel turístico que tienen los espacios situados fuera de núcleos de más de 1000 habitantes a partir de tres fuentes: material institucional, guías turísticas e imágenes creadas por usuarios de la red social Instagram. Se parte del caso de Uruguay para constatar una presencia testimonial de imágenes turísticas de espacios rurales. Una situación agudizada en guías turísticas y material institucional. Ello implica una imagen fragmentada, en la que buena parte del ámbito rural carece de imagen turística, mientras los espacios urbanos focalizan y retroalimentan las referencias disponibles.
\end{abstract}

Palabras Clave: Distribución espacial; Material turístico institucional; Guías turísticas; Contenidos generados por el usuario; Instagram; Uruguay.

The under-representation of non-urban areas. A comparison of printed materials and images on Instagram.

Abstract: The representative image of any place is fundamental when attempting to attract tourists. However, not all landscapes inside and outside the city are easily recognisable or identified. This study analyses the role of areas located outside the city centres with over 1000 inhabitants in attracting tourism as reflected in three different media: brochures, travel guides and user-generated content (Instagram). This spatial analysis approach is applied to Uruguay. We witnessed a very limited number of images for these areas, that are mainly rural, a situation which is particularly the case for travel guides and brochures. This implies a fragmented image, iwhere rural areas are invisible whereas urban spaces concentrate a considerable number of the locations photographed, consolidating the decontextualised urban tourism perspective.

Keywords: Spatial layout; Official tourist brochures; Travel guides; User-generated content; Instagram; Uruguay.

\section{Introducción}

La representación de los atractivos es una componente fundamental dentro de los criterios que llevan al turista a elegir un destino (Vienne et al., 2017; Garrod, 2008; Mackay y Couldwell, 2004). Ahora bien, no todos los territorios se proyectan con las mismas facilidades. Dentro del marco de unas imágenes globales, la singularización de un único destino es compleja. El número de localizaciones que es capaz de reconocer el conjunto de la población es extremadamente limitado. Las imágenes textuales de una región tienden a asociarse a pocos topónimos. Una representación de ello sería el caso de China. Pan y Lii (2011) mostraron como únicamente unos pocos topónimos, como Xi'an, Beijing o la Gran Muralla, eran conocidos por una parte amplia de la población. Una vez enumeradas estas localizaciones los ejemplos citados se diversificaban. Se incrementaban las lagunas en el conocimiento

Professor lector Serra Húnter, Departamento de Geografia y Sociologia - Facultad de Derecho y Economia; E-mail: dpaul@geosoc.udl.cat. 
del espacio, creando subjetividades que ayudaban a los ciudadanos a formar la imagen mental anhelada de país, pero que relegan a la mayoría de sus zonas al olvido o a una imagen fragmentada y alejada de la realidad.

La creación y gestión de la imagen de un territorio no es tarea fácil. Dependerá, en buena medida, de la capacidad de los gestores de cada localización para comunicar al público potencial las percepciones existentes sobre aquel espacio y sus habitantes (Paül i Agustí, 2014). En esta compleja relación el turista es simultáneamente productor y consumidos de imágenes (Urry, 1990). El presente estudio se centrará en esta relación. Se analizarán imágenes producidas por los propios turistas mediante la red social Instagram. Los resultados obtenidos se compararán con los proyectados por otros agentes, en este caso instituciones y guías turísticas.

Comparar imágenes de un mismo ámbito, pero procedentes de varias fuentes, genera una información relevante sobre la imagen proyectada por un espacio (Hunter, 2016). Así, el presente trabajo se inscribe en la línea de otros estudios que señalan cómo la imagen puede ser un elemento fundamental para valorar las relaciones existentes entre sociedades y territorios (Hall y Page, 2014). Se comparará la imagen turística generada por los distintos actores en Uruguay, poniendo una atención especial en las diferencias en la distribución entre espacio urbano y no urbano. Se pretende así tratar un aspecto poco presente en la literatura académica. La diferencia en el peso de la imagen turística del espacio urbano y del rural.

\section{Revisión bibliográfica}

Actualmente la mayoría de la población del planeta reside en ciudades $\left(54,3 \%\right.$ en $\left.2016^{1}\right)$. Uruguay no es una excepción, con un 95’5\% de la población urbana. Pese a ello, las ciudades únicamente ocupan una pequeña parte del territorio. Esta concentración de la población en las ciudades es un fenómeno relativamente reciente. Históricamente la población se encontraba más repartida por el conjunto del territorio. Estas dos características, difusión territorial y presencia histórica y continua de población, hacen que los espacios no urbanos tengan un potencial patrimonial elevado. No obstante, los cambios experimentados a partir de los años cincuenta han dificultado la visibilidad de este patrimonio.

Las relaciones de buena parte de la población urbana con el territorio no urbano tienden a ser puntuales y poco profundas (Paül i Agustí, 2016). Dado que la imagen tiende a reproducir símbolos con un significado que ha sido construido y difundido socialmente (Miossec, 1977) y basarse en percepciones individuales subjetivas construidas en la mente (Galí y Donaire, 2015), la limitada movilidad de la población urbana hacia los espacios no urbanos y su limitada presencia en los medios de comunicación puede conllevar un importante desconocimiento de estas áreas (Zhou, 2014).

La escasa relación con los espacios no urbanos por parte del grueso de la población dificulta la creación y reproducción de imágenes pertenecientes a estos ámbitos. Este proceso, a su tiempo, condiciona el conocimiento, el reconocimiento y la difusión de los elementos presentes susceptibles de conformar una imagen turística de los espacios no urbanos. Se genera así una representación no uniforme del territorio, en la que las ciudades tienden a una mayor presencia y el espacio no urbano desaparece del imaginario colectivo (Aldomà et al., 2017: 103).

El proceso que favorece la creación y la difusión turística de las imágenes se ha beneficiado de la proliferación de las redes sociales o la web 2.0 (Brandajs y Soro, 2017: 12). Para comprender mejor estos cambios es necesario analizar las nuevas relaciones y desequilibrios territoriales. En este contexto, los espacios se pueden analizar simultáneamente como puntos de encuentro de relaciones presenciales y a distancia (Massey, 2001). El turista ya no es un simple espectador. Es un actor que interactúa con los distintos espacios que visita (Tigre Moura et al., 2015; Coleman y Crang, 2002). El turismo deja de ser una simple circulación de individuos para generar también movimientos materiales y de imágenes.

En términos generales la literatura existente ha tendido a considerar los turistas con cámaras como personas dedicadas a repetir las fotografías visualizadas previamente en guías, websites, etc. (Stylianou-Lamber, 2012: 1817). Sin embargo, esta situación estaría cambiando. La diversificación de las motivaciones turísticas y el aumento de la capacidad para tomar imágenes habrían generado nuevos comportamientos. Cada turista tendrá sus propias expectativas y motivaciones, que implicarán comportamientos distintos. Ahora bien, ¿hasta qué punto podemos observar esta diversificación? Es cierto que ha existido un notable incremento del número de fotografías realizadas a medida que la 
fotografía se ha transformado en un evento social (Katsoni, 2014: 109). Ello ha favorecido los cambios discontinuos y la visión que, en ciertos casos, las fuerzas sociales pueden contribuir a rediseñar el espacio físico y los comportamientos en el área en la que se desplazan los turistas (Nielsen et al., 1995).

Así mismo, gracias a las imágenes disponibles en las redes sociales las fotografías realizadas por los turistas han podido ser estudiadas desde nuevas ópticas. A modo de ejemplo podemos citar algunos trabajos recientes focalizados en el proceso de creación de la imagen (Stylianou-Lamber, 2012), su temática (Donaire et al., 2014) o la experiencia de los usuarios (Hochman y Manovich, 2013). Ahora bien, son pocos los estudios que han entrado a analizar las localizaciones geográficas de las imágenes turísticas y el grado de interrelación existente con las imágenes difundidas por los medios tradicionales.

No todas las imágenes, y en consecuencia, no todos los territorios tendrán una representación igualitaria. Ciertos autores han mostrado como el turista tiende a compartir en las redes sociales únicamente ciertas visiones de los atractivos (Donaire, et al, 2014). Las redes sociales reproducen, así, elementos muy concretos, ayudando a la difusión y consolidación de una imagen turística muy definida y creando imágenes fijadas en el imaginario del turista.

La creación y fijación en el imaginario colectivo de las imágenes turísticas dependerá, por lo tanto, de varios filtros que se pueden concretar en aspectos como un hecho, una vivencia o, como en el presente estudio, un espacio concreto. El problema radica en cuando no existe ninguna imagen capaz de ser identificada por el turista. ¿Qué imágenes se reproducirán en estos espacios? Los condicionantes demográficos, históricos o de accesibilidad de los espacios rurales condicionan la creación de imágenes turísticas potentes, lo que puede llevar a un tratamiento territorial turístico distinto de estos espacios, como analizaremos en el presente artículo.

\section{Metodología}

\section{1. Ámbito de estudio}

La presente investigación se focaliza en la República Oriental del Uruguay. El país tenía, en 2015, 3.467.054 habitantes. La mayor concentración urbana correspondía al departamento de Montevideo, capital del país, que concentraba 1.379 .560 de habitantes (39,8\%). El país ocupa un área de $175.016 \mathrm{~km}^{2}$, de los cuales $530 \mathrm{~km}^{2}$ (0,3\%) corresponden al departamento de Montevideo. En el colindante departamento de Canelos residen 566.626 habitantes. Fuera del área de la capital, la población tiende a localizarse en los departamentos situados en el litoral atlántico y fluvial del país. No obstante, ninguno de los diecisiete restantes departamentos del país alcanza los 200.000 habitantes.

La densidad media de Uruguay es de $19,8 \mathrm{hab} / \mathrm{km}^{2}$. Ahora bien, si calculamos la media sin los dos departamentos citados anteriormente la densidad se sitúa en $11,45 \mathrm{hab} / \mathrm{km}^{2}$. En nueve departamentos la densidad es incluso inferior, no alcanzando los $7 \mathrm{hab} / \mathrm{km}^{2}$. Unos datos que apoyan la elección de la marca "Uruguay Natural" para la promoción del país y que muestran la escasa densidad de población de buena parte del territorio uruguayo, lo que ayuda a identificar claramente espacios no urbanos, objetivos del presente trabajo.

$\mathrm{Al}$ mismo tiempo, la actividad turística presenta un peso relevante en Uruguay alcanzando, en 2015, un peso de aproximadamente un 7\% del PIB. Durante el año 2016 el país tuvo 3,3 millones de llegadas de turistas extranjeros. El origen principal de los visitantes fue Argentina y Brasil. En cuando al destino elegido para la visita, Montevideo es el punto principal de atracción, visitado por el $31,6 \%$ de los turistas del país, seguido por la localidad costanera de Punta del Este (20,9\%). La zona costera de Piriápolis $(4,3 \%)$ y la ciudad de Colonia $(8,7 \%)$, declarada Patrimonio de la Humanidad por la Unesco, son otras áreas que reciben un volumen importante de turistas. Los restantes visitantes se reparten en varias localidades de las regiones costeras, como el litoral termal $(14,3)$, Rocha (4.9\%) o la costa del Oro $(4,3 \%)$. Los otros espacios del país tienen, en consecuencia, una presencia limitada de turistas, que una vez descontados los viajeros en tránsito, se situaría alrededor del $5 \%$ del total de visitantes (Sosa, 2016).

La presencia de una cifra importante de turistas, de varias tipologías y nacionalidad, junto con la presencia de atractivos variados como patrimoniales, naturales y paisajísticos, un buen nivel de servicios y ferias y festivales relevantes, hacen que Uruguay pueda ser un área excelente para valorar el comportamiento espacial de los turistas e identificar los recursos territoriales que el turista valora. Unas observaciones que pueden ser extrapolables a otras localidades. 


\subsection{Definición del ámbito urbano}

La diferenciación de los atractivos turísticos situados en espacios urbanos y no urbanos vendría condicionada por los límites existentes en la definición misma de estos espacios. En la actualidad existe en Uruguay un debate sobre qué se entiende por rural o por población dispersa (Piñeiro y Cardeillac, 2014; Cardeillac et al., 2016). De hecho, Uruguay presenta una particularidad en el contexto latinoamericano. A diferencia de otros países en los que la definición de rural se fija a partir de aspectos cuantitativos como la población o la densidad, en Uruguay el criterio es legal. La legislación basándose en criterios prácticos y operativos define la población urbana y, por exclusión, las poblaciones rurales (Faiguenbaum, 2011). Así, se considera como centro poblado (Ley 10.723, de centros poblados, artículo 13) los espacios con los siguientes requisitos mínimos: abastecimiento suficiente de agua, disponibilidad de tierras aptas para la agricultura intensiva en las proximidades, no situadas en terrenos inundables, y que constituyan, por lo menos, una unidad vecinal que permita el mantenimiento de una escuela primaria y de los servicios públicos indispensables.

Para la elaboración de la presente investigación se usaron los datos del Instituto Nacional de Estadística de Uruguay (INE) correspondientes al censo de 2011, último año disponible. En aquel censo se usó una división del país entre áreas amanzanadas o localidades censales y áreas no amanzanadas. En el presente estudio, siguiendo las definiciones usadas en el país, se distinguió entre espacios urbanos y no urbanos, definiendo los segundos por exclusión. El límite entre ambos se fijó en los 1.000 habitantes en un núcleo habitacional según los datos del censo de 2011 (Imagen 1). Esta división respeta los criterios usados tradicionalmente por el INE a partir de 1963 (Martínez, 2013).

Imagen 1: Distribución de la población por núcleos (2011)

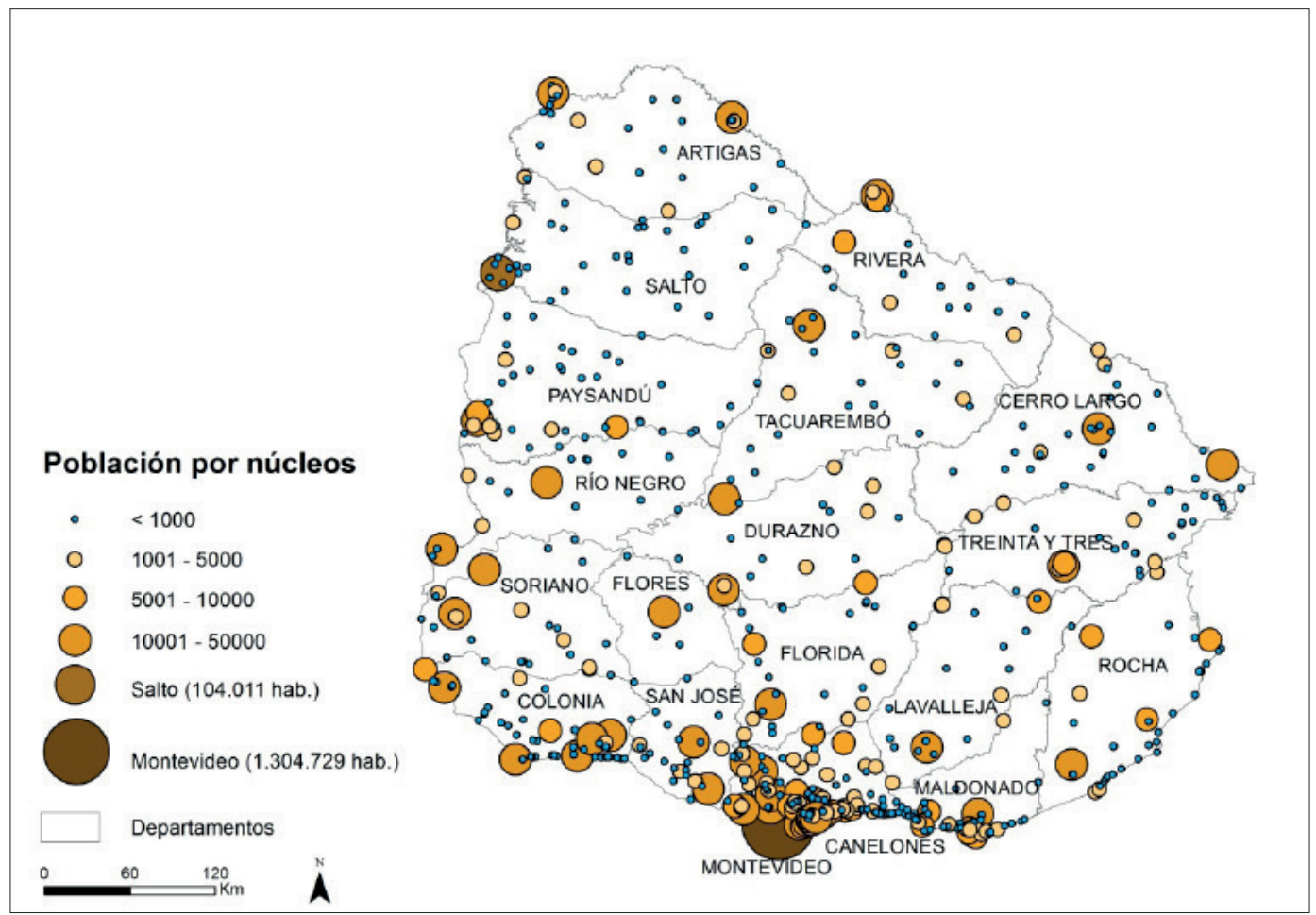

Fuente: elaboración propia. Base cartográfica INE Uruguay. 


\subsection{Información turística recopilada}

La información base para este estudio procede de tres fuentes. Material editado por las instituciones públicas, guías turísticas e imágenes generadas por los usuarios.

El material editado por las instituciones públicas se recopiló sobre el terreno durante los meses de febrero y marzo de 2017. Durante este período se visitaron dos veces cada una de las seis oficinas de turismo existentes en el área metropolitana de Montevideo (tres gestionadas por el ministerio de turismo, dos de la Intendencia y una municipal). Siguiendo la metodología de Stylianou-Lamber (2012: 1824) se consideró que la muestra estaba completa, y en consecuencia se podía considerar como representativa, cuando nuevas visitas a las oficinas no aportaron nuevo material a la muestra. Se obtuvieron varios mapas y guías, tanto de carácter general como temáticas. La mayoría del material estaba editado por el ministerio de turismo. Únicamente localizamos algunas publicaciones puntuales editadas por las distintas intendencias locales.

En cuanto a las guías turísticas se analizó la información contenida en las guías editadas en castellano. Se vaciaron todas las guías disponibles en el mercado editadas a partir del año 2010: Anaya Touring (Pagella, 2013), Bradt (Burford, 2011), Lonely Planet (Bao, 2015) y Guía Azul (Monreal, 2012).

Del material editado por las instituciones públicas y de las guías turísticas se realizó un vaciado del conjunto de la información que contenían. Se identificaron los atractivos que se promocionaban, su localización y algunos datos más cuantitativos. Los datos obtenidos se cuantificaron en función de una fórmula que reflejase el peso de la información. Concretamente se siguió la propuesta de Serrano y Imbert-Bouchard (2009: 391) que matizaba el peso en función de aspectos como la extensión de la explicación del atractivo, la presencia de imágenes, la inclusión de mapas o el tratamiento objetivo o subjetivo del atractivo:

Índice de impacto $=\left(\left(\mathrm{A}^{*} 10 / \mathrm{Amax}\right)^{*} 0,4\right)+\left(\left(\mathrm{B}^{*} 10 / \mathrm{Bmax}\right)^{*} 0,2\right)+\left((\mathrm{C} * 10 / \mathrm{Cmax})^{*} 0,2\right)+\left(\left(\mathrm{D}^{*} 10 / \mathrm{Dmax}\right)^{*} 0,2\right)$

A = Número de palabras de la descripción del atractivo

$\mathrm{B}=$ Dimensión de las imágenes relacionadas con el atractivo

$\mathrm{C}=$ Mapa o croquis de localización del atractivo

$\mathrm{D}=$ Tratamiento objetivo / subjetivo del atractivo

Las dos fuentes de información anteriores se podían vaciar en su totalidad. Un hecho imposible en la tercera fuente, la red Instagram. Por este motivo fue necesario acotar la información que se quería analizar. Instagram es una red social para compartir imágenes y comentarios asociados. Las imágenes pueden compartirse de forma pública o privada. En la presente investigación únicamente hemos utilizado las imágenes de carácter público. Por lo tanto, este no es un estudio de todas las imágenes turísticas sino de aquellas imágenes que los usuarios deciden compartir en Instagram.

Instagram permite una búsqueda preliminar de los lugares donde han sido tomadas las fotografías. En nuestra investigación hemos utilizado tres localizaciones "Montevideo", "Ciudad de Montevideo" y "Uruguay". A pesar de existir otras localizaciones territoriales los tres topónimos elegidos eran las que presentaban mayor nivel de actividad en el Uruguay. Concretamente, "Montevideo" generaba unas 1.200 fotografías diarias, "Ciudad de Montevideo" unas 250 y "Uruguay" unas 2.000 al día.

En el presente estudio hemos analizado las imágenes generadas en dos momentos. Del 1 al 15 de noviembre de 2016 y del 8 al 25 de febrero de 2017. La elección de estos dos momentos busca evitar la estacionalidad turística. La recopilación de la información también siguió la metodología de Stylianou-Lamber (2012: 1824). Se consideró que la muestra era representativa cuando el vaciado de un nuevo día no incorporaba nuevos elementos turísticos a la base. En total se analizaron unas 107.000 imágenes, de las que 11.261 fueron localizadas en el mapa. Una cifra en línea con la de otros estudios basados en las redes sociales, como el de Galí \& Donaire (2015), basado en 34.200 imágenes de Flickr, o el de Stylianou-Lambert (2012), focalizado en 400 imágenes de Flirck y Picasa.

El primer filtro para clasificar las imágenes fue descartar aquellas imágenes generadas por los residentes. Para identificar a los residentes se usó la información del perfil disponible en Instagram, la lengua en la que se escribían los mensajes y las actitudes y posturas en las imágenes. Si la identidad del fotógrafo no quedaba suficientemente clara, se descartaba la imagen. Siguiendo la metodología de Stylianou-Lamber (2012: 1825) para evitar la subjetividad se establecieron una serie de pautas y se hizo una prueba piloto. En ella, dos personas codificaron 20 imágenes. En nuestro caso, el grado de coincidencia inicial fue del 90\%. Después de discutir las diferencias se homogeneizaron y clarificaron 
los conceptos. Cuando se repitió la prueba con nuevas imágenes, la coincidencia en la codificación fue del 95\%. Esta codificación permitió identificar que los turistas eran responsables de un 19,7\% de las imágenes (21.082 imágenes).

El siguiente filtro era identificar las imágenes que podían ser localizadas en el mapa. Para hacerlo usamos la metodología comentada por Donaire, Camprubí \& Galí (2014), basada en el análisis de contenidos. El análisis de contenidos se puede definir como un método observacional usado para evaluar sistemáticamente el contenido simbólico de todas las formas de comunicación que puedan grabarse (Hall y Valentin, 2005). Debe ser objetivo, sistemático y generalista para garantizar así la confiabilidad y replicabilidad de los estudios (Holsti, 1968).

El primer criterio fue descartar las imágenes que no permitían identificar la localización. En este sentido, se adaptó la idea de "eye-catchers". Se consideran "Eye-catchers" una ilustración donde el 50\% o más de la imagen está ocupada por un elemento que capta la atención (Pritchard y Morgan, 1995: 28). Se descartaron aquellas imágenes en las que el 50\% del espacio estuviese ocupado por elementos que no fuesen territorializables: caras (selfies), detalles, puestas de sol, nubes, etc. Aproximadamente un tercio de las imágenes correspondían a esta categoría.

Para las 15.036 imágenes restantes se buscó su localización en el mapa. Para ello se usaron cuatro vías:

- Comentarios presentes en la aplicación, en los que se identificaban directamente los lugares.

- Reconocimiento de localizaciones en las diversas imágenes (fotografías con nombres de comercios, direcciones, etc.).

- Análisis a través de la aplicación Google images, la cual permite hacer búsquedas por imagen. Los resultados muestran páginas con imágenes similares, donde a menudo aparece la localización.

- Para las imágenes que no era posible identificar con los métodos anteriores, se contactó con varios especialistas con un elevado conocimiento del ámbito turístico uruguayo.

Finalmente se localizaron en un sistema de información geográfico 11.261 imágenes, un 74,9\% de las imágenes territorializables colgadas por los turistas en Instagram en el periodo examinado. Para las imágenes creadas por los usuarios se elaboró un índice de impacto que, adaptándolo a la información de la fuente, respectase el índice utilizado en las guías y el material institucional.

Índice de impacto $=\left(\left(\mathrm{A}^{*} 10 / \mathrm{Amax}\right)^{*} 0,4\right)+\left(\left(\mathrm{B}^{*} 10 / \mathrm{Bmax}\right)^{*} 0,2\right)+\left(\left(\mathrm{C}^{*} 10 / \mathrm{Cmax}\right)^{*} 0,2\right)+\left(\left(\mathrm{D}^{*} 10 / \mathrm{Dmax}\right)^{*} 0,2\right)$

A = Número de palabras de la explicación

$\mathrm{B}=$ Número de likes

$\mathrm{C}=$ Número de hashtags

$\mathrm{D}=$ Tratamiento como Top Post $(\mathrm{Dmax}=1)$

\section{Resultados}

\subsection{Presentación}

Un primer aspecto a enumerar de los resultados es el número de atractivos turísticos que se han identificado. Como se puede observar en la tabla 1, el grueso de los atractivos se localizaban en el departamento de Montevideo (63\%). En los dieciocho restantes departamentos del país únicamente hemos identificado 295 atractivos turísticos. Una cifra que ya nos expone un primer dato sobre la concentración de los atractivos en los espacios urbanos, especialmente en el área metropolitana de la capital.

Un segundo aspecto observable en la tabla es el número de atractivos identificados en cada una de las fuentes analizadas. En todos los ámbitos Instagram era la fuente que permitía identificar más elementos. Así, del total de 796 atractivos identificados, 700 (87,9\%) aparecían en Instagram. Ahora bien, mientras que en el Departamento de Montevideo Instagram identificaba más de 2'6 veces el número de atractivos del material institucional o de las guías, en los otros casos la proporción era generalmente menor del doble. En consecuencia podemos apuntar que el material editado (guías y material institucional) únicamente muestra un número limitado de los aspectos que los turistas consideran de interés fotográfico. 
Tabla 1: Número de atractivos identificados

\begin{tabular}{|c|c|c|c|c|}
\hline Atractivos citados & $\begin{array}{c}\text { Departamento de } \\
\text { Montevideo }\end{array}$ & $\begin{array}{c}\text { Núcleos } \\
>1000 \text { habitantes }\end{array}$ & $\begin{array}{c}\text { Otras áreas del } \\
\text { país (1) }\end{array}$ & Total \\
\hline $\begin{array}{c}\text { Material } \\
\text { institucional }\end{array}$ & 173 & 62 & 102 & 337 \\
\hline Guías turísticas & 174 & 51 & 72 & 297 \\
\hline Instagram & 455 & 91 & 154 & 700 \\
\hline Total & 501 & 102 & 193 & 796 \\
\hline
\end{tabular}

(1) Atractivos turísticos cuya localización no coincide con los núcleos de más de 1000 habitantes definidos por el INE en el censo de 2011.

En tercer y último lugar la tabla 1 permite observar diferencias territoriales. Montevideo, la capital, concentra buena parte de los atractivos. Fuera de esta área, los espacios con menos de 1000 habitantes son los que tienen, en conjunto, más atractivos (193). Finalmente, los núcleos de más de 1000 habitantes situados fuera del departamento de Montevideo son los menos representados (102). En consecuencia, podemos apuntar que ser ciudad no garantiza, por sí mismo, una presencia importante en la proyección turística. Salvo Montevideo, los restantes núcleos de población del Uruguay no muestran un volumen de atractivos significativo.

Las afirmaciones anteriores se matizan si se analiza el índice de impacto de los atractivos. La correlación estadística entre las tres fuentes analizadas nos señala unos valores positivos en el conjunto de los resultados (nivel de confianza 95\%, margen de error 5\%, correlación significativa al 99,9\% p<0,01). Así, los valores más elevados se obtienen en la correlación entre el material institucional y las guías turísticas $(0,665)$. También observamos valores positivos en la correlación de las imágenes creadas por los usuarios en Instagram con las del material institucional $(0,541)$ y con las de las guías turísticas $(0,500)$. En este sentido, el grado de asociación positivo entre las distintas fuentes analizadas señala un comportamiento similar en el tratamiento de la imagen turística de los espacios no urbanos, con mayor homogeneidad entre material institucional y guías turísticas. Pese a ello existen algunas diferencias significativas.

En primer lugar, como se puede observar en el gráfico 1, los atractivos identificados en Instagram tienden a presentar unos valores claramente superiores a los del material editado, fruto de la mayor repetición de atractivos y de unas explicaciones generalmente más detalladas. Además, mientras guías turísticas y material institucional presentan una tendencia generalmente decreciente, en la que son pocos los atractivos que presentan un índice de impacto elevado (el valor más habitual es uno), Instagram presenta más variabilidad (el valor más habitual es tres).

En Instagram los valores con un índice de impacto más bajo no son los más habituales. Mientras que el material impreso tiende a seguir una estructura en la que unos pocos atractivos tienen los índices de impacto más elevados y a medida que aumenta el número de atractivos, el interés del público es más segmentado (siguiendo el modelo propuesto por Pan y Li, 2011, 132), en el caso de Instagram la relación es menos lineal. Se repite la presencia limitada de los atractivos con un índice de impacto más alto, pero se incorporan matices. Así, son relativamente pocos los atractivos con un índice de impacto de uno, mientras que los que obtienen un índice de impacto de tres son clara mayoría. Entre las causas de esta situación podríamos encontrar las imágenes puntuales y extremamente especializadas, pero con escasa repercusión en el conjunto de la red, que generaría Instagram. Unas imágenes hiperespecializadas que tendrían un índice de impacto escaso. Ahora bien, imágenes susceptibles de contribuir a generar una determinada imagen turística. 
Gráfico 1: Distribución de los atractivos en función del índice de impacto.
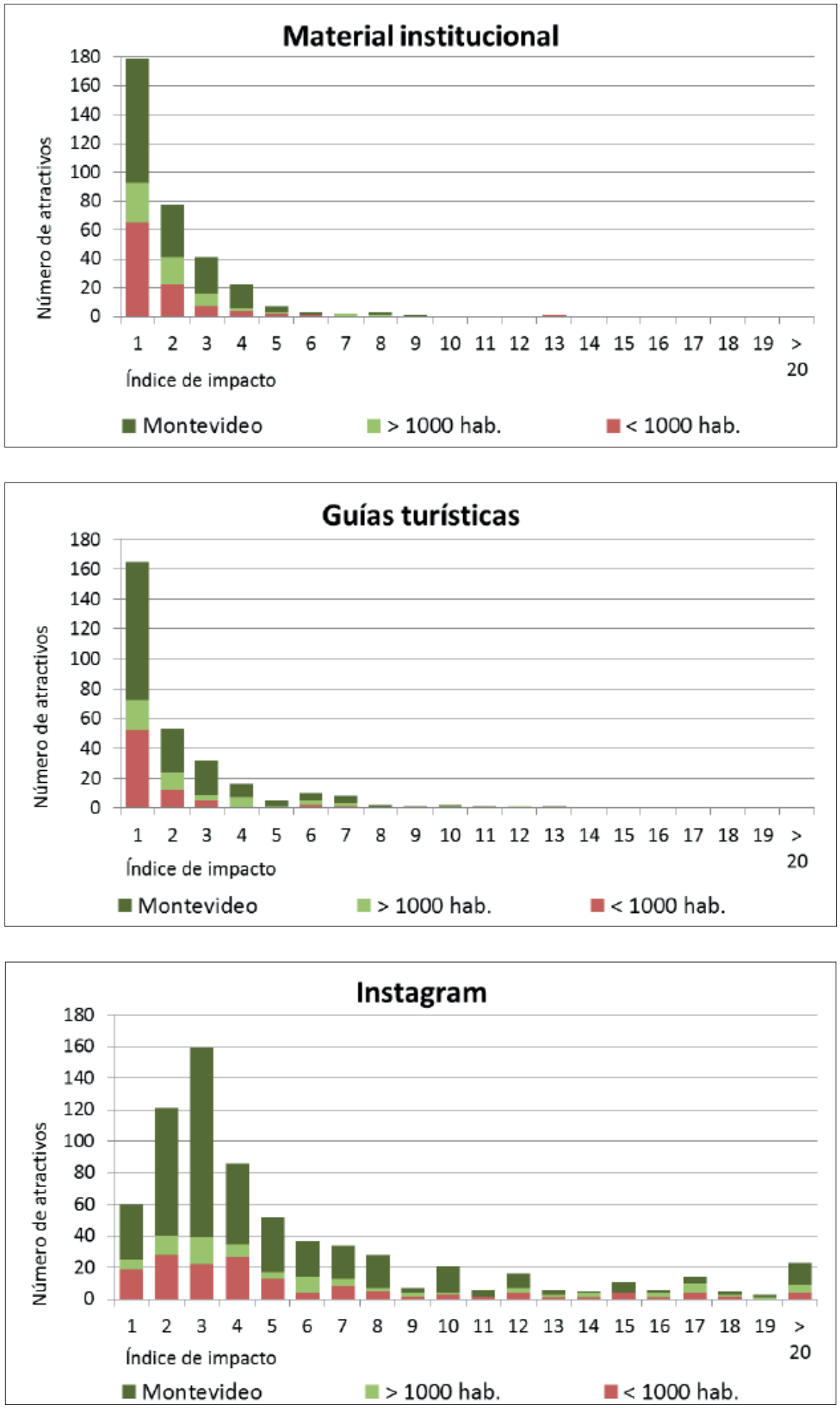

Fuente: elaboración propia 


\subsection{Localización de los atractivos}

Una vez identificados los atractivos se localizaron territorialmente diferenciando los resultados obtenidos en función de la fuente: material institucional (imagen 2), guías turísticas (imagen 3) e imágenes generadas por los usuarios (imagen 4).

El material institucional (imagen 2), como las otras fuentes analizadas, tendía a presentar una importante concentración de los atractivos en el departamento de Montevideo, tanto en número de atractivos identificados como en su índice de impacto (presencia de fotografía, explicación detallada, etc.).

Fuera del departamento de la capital observamos que el material institucional presenta unos valores más elevados del índice de impacto en las ciudades principales, especialmente en:

- Las distintas capitales departamentales, que tienden a ser objeto de un tratamiento muy similar. La promoción institucional tiende a recopilar las principales iglesias, edificios administrativos y museos de las distintas localidades, haciendo una descripción básicamente artística del atractivo.

- Las ciudades declaradas patrimonio de la Humanidad: Colonia del Sacramento y Fray Bentos. Estas dos ciudades tienen una presencia destacada, basada precisamente en la protección de la UNESCO.

- Ciudades costeras, con un reconocimiento turístico importante, como Punta del Este, Piriápolis o la Paloma

Podemos señalar, en consecuencia, que la promoción institucional de los núcleos de más de 1000 habitantes tiende a repetir la estructura administrativa, priorizando aquellos núcleos que disponen de funciones administrativas (por ejemplo, sedes municipales o departamentales) o bien que han tenido, históricamente, un reconocimiento turístico importante.

Imagen 2: Atractivos identificados en el material institucional (índice de impacto)

\section{Atractivos en material institucional}

Núcleos

$>1.000$ habitantes

Núcleos

$<1000$ habitantes

$\circ 1$

○ 2 - 3

○ $4-5$

$6-7$

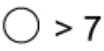

Departamentos
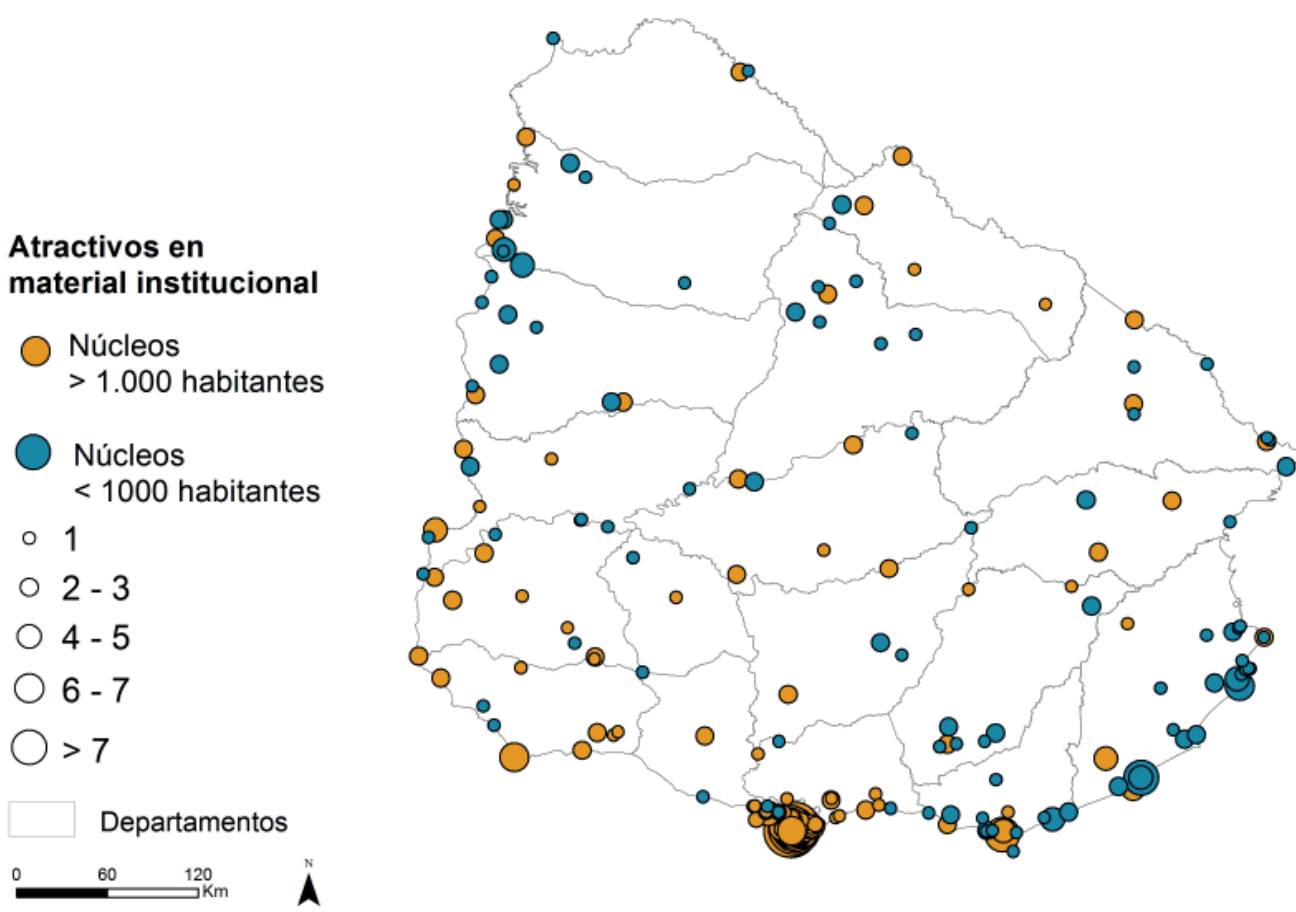

Fuente: elaboración propia. Base cartográfica INE Uruguay. 
Por el contrario, en el caso de las áreas con menos población los atractivos localizados tienden a implantarse en dos áreas. En primer lugar, el litoral atlántico, al este del país, especialmente en los departamentos de Maldonado y sobretodo Rocha, con especial relevancia en el entorno de Cabo Polonio y Chuy. En segundo lugar, al oeste del país, a lo largo de la frontera con Argentina, en lo que se ha venido promocionando en los últimos años como "Corredor de los Pájaros Pintados". Los atractivos de cada una de estas dos áreas tienden a promocionarse de manera conjunta, creando una imagen turística sobre la base de la suma de atractivos no urbanos.

Fuera de estos dos espacios, los atractivos turísticos promocionados por los medios oficiales tienden a ser escasos. Únicamente hemos identificado 36 atractivos, de los cuales el 50\% se encuentran a menos de $30 \mathrm{~km}$ de un atractivo situado en un núcleo de más de 1000 habitantes, con los que se tienden a promocionar conjuntamente. En consecuencia, podemos afirmar que la promoción institucional de atractivos situados en ámbitos no urbanos tiende a realizarse prioritariamente de manera mancomunada. Pese a ello, la difusión de atractivos singulares situados en áreas no urbanas es extremadamente limitada y tiende a tener un índice de impacto bajo.

Las guías turísticas fueron la fuente que, como hemos señalado, incorporaba menos atractivos (imagen 3). Pese a localizar un número similar de atractivos al del material institucional en el Departamento de Montevideo, fuera de esta área el número de atractivos identificados fue únicamente de 123.

La distribución de los atractivos seguía un patrón similar al del material institucional en la mayoría de los casos. Se mantiene el predominio en número de atractivos e índice de impacto de Montevideo, de las ciudades principales y, en buena medida, del conjunto de ciudades con más de 1000 habitantes.

Así, la principal diferencia con el material institucional es que son extremadamente escasos los atractivos localizados fuera de áreas con más de 1000 habitantes. Estos espacios únicamente mantienen volúmenes importantes de atractivos identificados en los departamentos de Maldonado y Rocha. El número de atractivos identificados en el "Corredor de los Pájaros Pintados" es extremadamente limitado y a menudo

\section{Imagen 3: Atractivos identificados en las guías turísticas (índice de impacto)}

\section{Atractivos en guías turísticas}

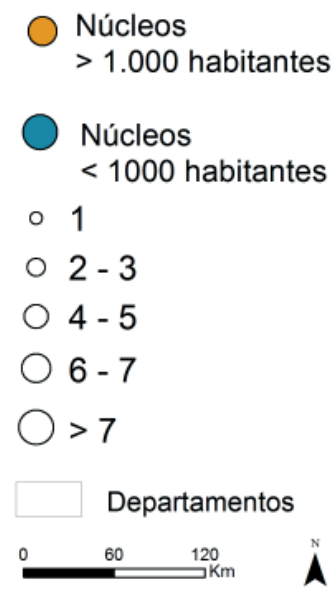

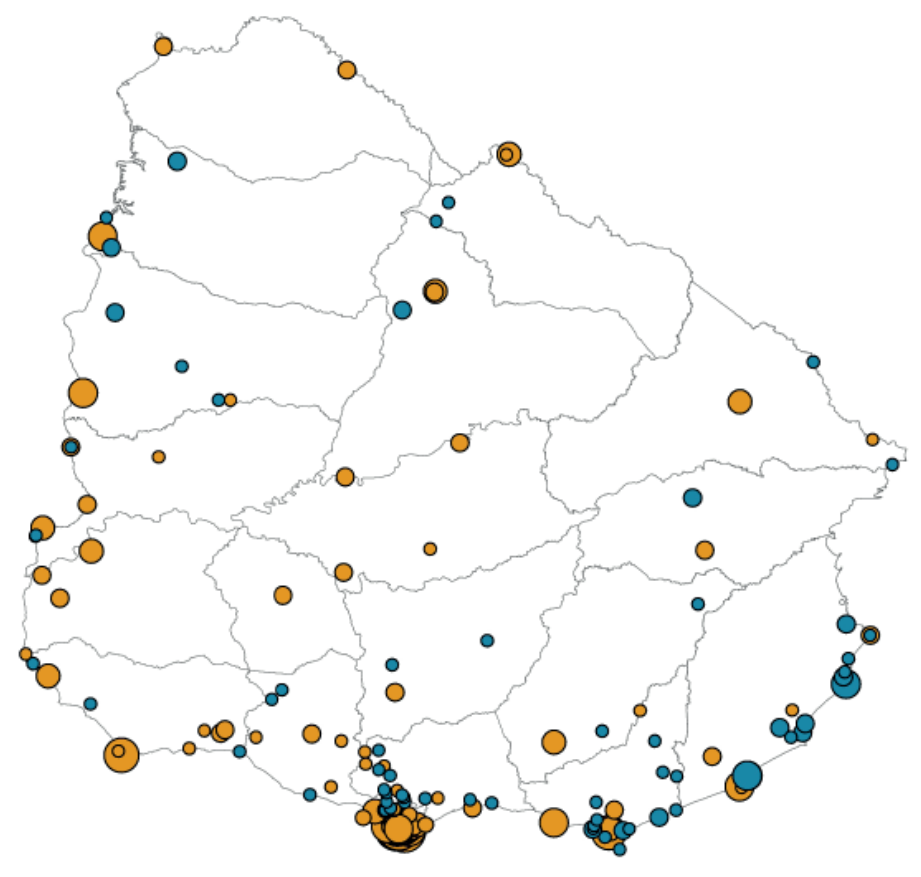

Fuente: elaboración propia. Base cartográfica INE Uruguay. 
asimilado a los distintos balnearios de la región. La novedad de la promoción institucional del producto podría explicar esta diferencia, e indicar todavía un escaso posicionamiento en las guías turísticas.

Fuera de los espacios litorales y del corredor, el número de atractivos rurales identificados en las guías es extremadamente limitado. Únicamente ocho atractivos, de los cuales cuatro en relación directa con un núcleo de más de 1000 habitantes. Además, los índices de impacto de estos atractivos son por lo general bajos. En consecuencia, podemos señalar que la visión del Uruguay que promocionan las guías turísticas es extremadamente urbana, con un peso de los atractivos situados fuera de los núcleos principales de población extremadamente limitado.

La situación anterior no implica, no obstante, que no existan espacios susceptibles de interés turístico fuera de los núcleos de más de 1000 habitantes. El análisis de las imágenes creadas por los usuarios (Imagen 4) mantiene ciertas coincidencias, como la importancia de los atractivos del departamento de Montevideo, de las capitales departamentales y de las ciudades patrimonio de la humanidad. Estas localidades obtienen unos valores elevados en el índice de impacto, en línea con los observados en las otras fuentes analizadas.

\section{Imagen 4: Atractivos identificados en las imágenes de los usuarios (índice de impacto)}

\section{Atractivos en Instagram}

$\begin{aligned} & \text { Núcleos } \\ & >1.000 \text { habitantes }\end{aligned}$
$\begin{aligned} & \text { Núcleos } \\ & <1000 \text { habitantes }\end{aligned}$
$0 \quad 1$
$02-3$
04 - 5
6 - 7
$>7$
$\quad$ Departamentos
$60 \quad$ Km

Fuente: elaboración propia. Base cartográfica INE Uruguay.

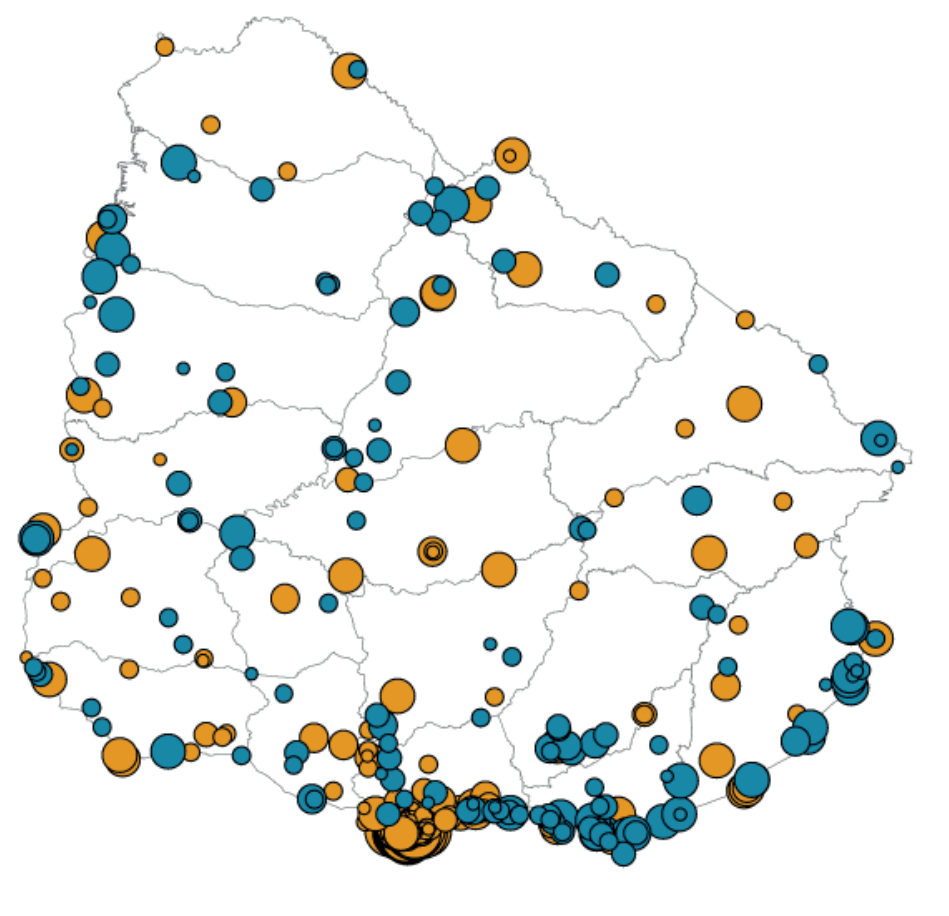

En el caso de los otros núcleos de población con más de 1000 habitantes, la situación difiere en algunos aspectos. En términos generales, el índice de impacto de estos núcleos tiende a ser mayor en los núcleos ya señalizados. Así mismo, tienden a incorporarse la mayoría de municipios de más de 1000, incluso aquellos que no aparecían ni en el material institucional, ni en las guías turísticas. En estos casos las imágenes más habituales tienden a ser las de plazas o bien, las estaciones ferroviarias.

Así mismo, el número de atractivos en áreas rurales también aumenta en número y muy especialmente, en índice de impacto. Así, mientras que en las anteriores fuentes los valores de estas áreas eran 
claramente inferiores a los de los espacios con más de 1000 habitantes, en las imágenes creadas por los usuarios los valores tienden a ser comparables (exceptuando los observados en Montevideo).

El incremento se constata en las distintas áreas identificadas en las anteriores fuentes. En el caso del litoral Atlántico encontramos algunos nuevos atractivos, especialmente en el departamento de Maldonado, y muy especialmente, un incremento de los valores relacionados con el índice de impacto. Así, varios de los espacios rurales identificados obtienen un índice de impacto comparable al de las capitales departamentales o al de espacios turísticos relevantes. Un aspecto que no observábamos en las anteriores fuentes y que indicaría un interés de los turistas por estos espacios muy superior al observado en las descripciones de las guías turísticas y el material institucional.

La misma situación se repite en el "Corredor de los Pájaros Pintados", con algunos matices. Así, pese a observar un buen número de atractivos y un índice de impacto elevado, el número de atractivos localizados en las imágenes generadas por los usuarios es restringido. Destaca, especialmente, que no se encontrase en las imágenes de Instagram ninguna referencia a localidades que sí que aparecen en el material institucional. Estas localidades son de varias tipologías: núcleos importantes como Constitución (2.762 habitantes), otros núcleos como Belén (947 habitantes) o espacios naturales como los Esteros de Farrapos. Esta presencia en el material institucional, que no viene respaldada por las imágenes creadas por los usuarios, no deja de ser sorprendente. Debemos recordar, no obstante, que el Corredor se encuentra actualmente en promoción. Podemos estar ante nuevos atractivos, poco conocidos en la actualidad, y que se pretende promocionar de cara al futuro.

Finalmente, los otros atractivos localizados en las imágenes creadas por los usuarios se dividen en dos grupos prácticamente del mismo peso. Atractivos en espacios rurales próximos a núcleos de población de más de 1000 habitantes y atractivos aislados. Entre los primeros, que representan un $60 \%$ de los atractivos de esta categoría, destacan especialmente los localizados en las cercanías de Paso de los Toros (12.985 hab., centro del país, próximo a la represa de Rincón del Bonete) y de Minas (38.446 hab., capital del departamento de Lavalleja).

Nuevamente, los atractivos situados en espacios no urbanos y desvinculados de grandes marcas representan una minoría. Los usuarios de Instagram únicamente habrían identificado 19 atractivos en estas categorías. Pese a que la cifra es la más elevada de las tres fuentes analizadas, los datos indican una escasa capacidad de estos espacios para crear una imagen turística fuerte. De hecho, el índice de impacto de estos atractivos se sitúa en la franja baja, destacando únicamente el parque Bartolomé Hidalgo (en el embalse de Paso del Palmar y en una de las principales vías de comunicación del país) y la antigua estación de Pampa, en el departamento de Tacuarembó.

\subsection{Síntesis de los resultados}

La síntesis en un mapa (imagen 5) de los resultados de las tres fuentes analizadas, guías turísticas, material institucional e imágenes generadas por los usuarios, muestra el escaso peso de los atractivos localizados en áreas con menos de 1.000 habitantes.

Como se puede observar las imágenes turísticas identificadas en las zonas no urbanas únicamente alcanza una presencia importante, tanto cuantitativamente, como a nivel de índice de impacto, en el litoral de los departamentos de Maldonado y Rocha, en el litoral atlántico. A mucha distancia, el litoral del "Corredor de los Pájaros Pintados" también presenta cierta relevancia. En las otras localidades del país la presencia de atractivos correspondientes a los espacios no urbanos puede ser considerada como testimonial.

La distribución de los atractivos tiende a ser comparable en los distintos departamentos del país. Pese a ello, observamos algunas pequeñas diferencias. Por ejemplo, la presencia de ciertos atractivos en los alrededores de Montevideo únicamente reseñados en las guías turísticas o el peso que el material institucional da a los dos espacios comentados anteriormente. En cambio, las imágenes creadas por los usuarios tienden a ser las que presentan una mayor difusión por el territorio. Pese a ello, podemos observar el peso limitado de los atractivos identificados en los espacios no urbanos.

En este sentido, existen amplias zonas de departamentos como Flores, Durazno, Artigas, Florida, Lavalleja, Treinta y Tres, Tacuarembó, Florida o Cerro Largo, en los que no hemos identificado, en ninguna de las fuentes analizadas, ninguna imagen turística. Este punto nos señala la dificultad existente para crear imágenes turísticas relevantes en estos espacios. Pese a ello, la existencia en otras zonas comparables de atractivos identificados, sobre todo en las imágenes creadas por los usuarios, muestra cierto potencial turístico de estos espacios. En este sentido, las imágenes de los usuarios tienden a mostrar una distribución más amplia de los atractivos del Uruguay y pueden ser un buen medio para 


\section{Imagen 5: Atractivos identificados fuera de los núcleos de más de 1.000 habitantes (índice de impacto)}

\section{Atractivos no urbanos}
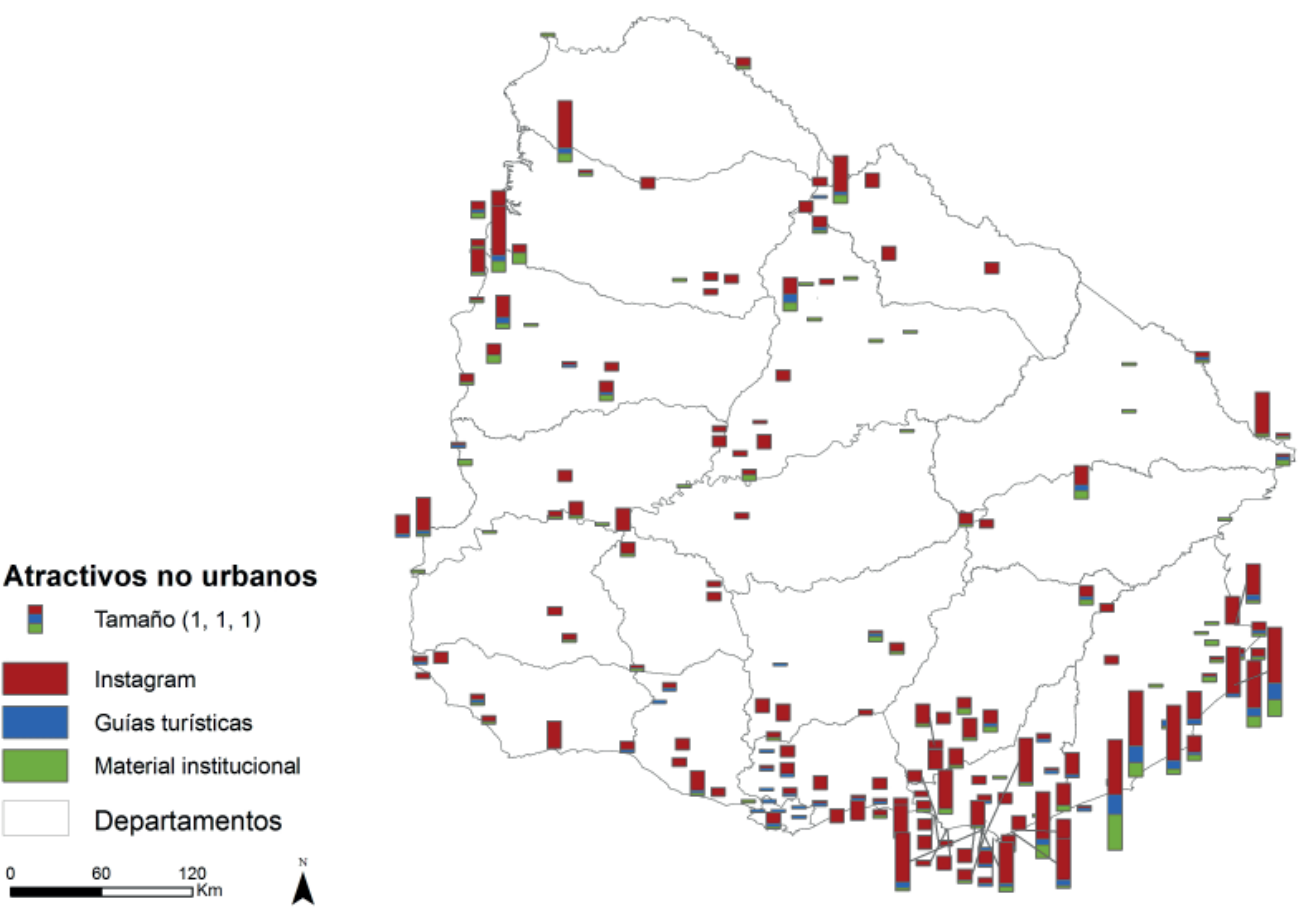

Fuente: Elaboración propia. Base cartográfica INE Uruguay.

identificar posibles puntos con potencial turístico y una escasa presencia en los medios tradicionales. Aspectos que pueden ayudar a reformular la imagen turística del territorio. Un aspecto que no hemos identificado en las guías turísticas ni en buena parte del material promocional.

\section{Conclusiones}

Los resultados obtenidos en el presente artículo muestran como las ciudades concentran las imágenes conocidas, situándose en los espacios más altos de la jerarquía turística descrita por autores como Pan y Li (2011). En cambio, los espacios no urbanos incorporan un amplio número de imágenes, pero únicamente reconocidas por pocos turistas. En este sentido, la coincidencia de los resultados espaciales uruguayos con los señalados por Pan y Li en su análisis textual de los atractivos turísticos de China apuntaría a un modelo jerárquico que iría más allá de los textos, para reproducirse en las imágenes.

La localización espacial de los atractivos uruguayos permite constatar una presencia focalizada en los espacios urbanos, especialmente la capital, su entorno más inmediato y las distintas capitales departamentales. En este contexto, las imágenes de los espacios rurales son extremadamente puntuales, desconectadas entre sí, y con un escaso peso con lo que difícilmente podrán contribuir a mejorar la imagen turística de estos espacios (Zhou, 2014).

Esta situación es especialmente visible en las guías turísticas. En el caso del material institucional, existe cierta voluntad por promocionar espacios fuera de los núcleos urbanos. Ahora bien, los resultados observados muestran una ambición limitada territorialmente y con una intensidad (índice de impacto) también limitada. Finalmente, pese a que las imágenes generadas por los usuarios son las que identifican un mayor número de atractivos fuera de los espacios urbanos, su presencia también es residual. 
Significativamente, esta carencia de imágenes de espacios no urbanos es aún mayor si nos focalizamos en los espacios que distan más de 30 quilómetros de un núcleo urbano.

Los datos anteriores muestran las dificultades por articular una imagen turística asociada a los espacios no urbanos que pueda ser, en la línea de los señalados por Urry (1990) fácilmente reproducida por los turistas. Los atractivos identificados en estos espacios tienden a ser elementos aislados, con una promoción más relacionada con los espacios urbanos que con los elementos patrimoniales, históricos o culturales del espacio colindante con los que comparte tradición. La única excepción localizada es la apuesta institucional, relativamente reciente, por el "Corredor de los Pájaros Pintados". Ahora bien, sin una promoción conjunta difícilmente un único punto aislado, desconocido del gran público, podrá generar un flujo de actividad suficiente para ser considerado un atractivo turístico.

Esta afirmación es especialmente sorprendente en un país cuya marca turística es "Uruguay Natural". En este sentido, la imagen turística proyectada dista mucho de contribuir a fortalecer la identidad colectiva de los espacios no urbanos. Los datos analizados muestran como la promoción turística de guías y material institucional tiende a reproducir criterios demográficos o económicos y prestar escasa atención a aquellas áreas sin presencia relevante de población. Incluso cuando la promoción busca cierto equilibrio territorial la solución implantada es enumerar los principales núcleos urbanos. Ello conlleva un claro decrecimiento de los puntos de interés promocionados a medida que se incrementa la distancia espacial a estos a núcleos. Un criterio discutible, que crea vacíos turísticos en importantes partes del país y que podría verse como una de las causas que impulsan un turismo básicamente urbano, centrado en un número muy limitado de espacios, con los riesgos de masificación que este aspecto conlleva.

En el caso de las imágenes de usuarios esta relación no es tan directa y muestra como existiría potencial para una promoción más equilibrada de los atractivos del país. En todo caso, resulta muy difícil pensar que una parte importante del país carece de elementos históricos, naturales, patrimoniales, festivos o de otro tipo susceptibles de ser objeto de promoción turística. En este sentido, como señalan Nielsen et al. (1995), la localización de imágenes creadas por los usuarios más allá de los puntos difundidos por el material impreso es un ejemplo del potencial de ciertos espacios rurales para transformarse en atractivos turísticos.

Queda claro que el espacio rural tiene dificultades importantes para incorporarse a la oferta turística promocionada por guías y material institucional. Ahora bien, las diferencias observadas con el comportamiento de los usuarios de Instagram apuntarían hacia un posible cambio que puede llevar, progresivamente, a una mayor incorporación de estos espacios en la oferta turística. Una buena gestión contribuiría a que pasasen de ser objeto de excursiones de un día desde las ciudades principales, a desarrollar una oferta global, capaz de alojar varias actividades turísticas. Un cambio que contribuiría a diversificar la actividad económica, revalorizar el patrimonio o aumentar la autoestima de los habitantes de estas áreas. En este sentido, Instagram se muestra como una herramienta de ayuda a los gestores territoriales del turismo, identificando nuevos puntos de interés de los turistas más allá de una promoción más tradicional y continuista, basada en criterios políticos y de homogeneidad territorial que tienden a favorecer las capitales administrativas de las distintas regiones.

\section{Agradecimientos}

El trabajo se integra dentro del proyecto financiado por el Plan Nacional "La gestión espacial de la conflictividad social" (CSO2015-64643-R) y en el Grup de Recerca Consolidat "Territori i Societat" de la Generalitat de Catalunya (2017 SGR 1450). El desplazamiento a Uruguay fue posible gracias a las "Becas Iberoamérica. Santander Investigación 2016". Se agradece la colaboración de la profesora Rossana Campodónico, de la Universidad de la República (Uruguay).

\section{Bibliografía}

Aldomà Buixadé, I.; Módol Ratés, J.R. y Guerrero Lladós, M.

2017. Patrimonis rurals. Reconeixement i perspectives. Lleida: Fundació del Món Rural.

Bao, S. (dir.)

2015. Argentina y Uruguay. 5a edición. Barcelona: GeoPlaneta.

Brandajs, F. \& Soro, E.

2017. Turisme, mobilitat i sostenibilitat. Barcelona: Fundació Universitat Oberta de Catalunya. 
Burford, T.

2011. Uruguay Barcelona: Alhenamedia.

Cardeillac, J.; Mascheroni, P. y Vitelli, R.

2016. Investigación sobre definición operativa de la población "rural" con fines estadísticos en Uruguay.

Montevideo: Organización de las Naciones Unidas para la Alimentación y la Agricultura (FAO) y

Departamento de Sociología de la Universidad de la República.

Coleman, S. y Crang, M.

2002. Tourism. Between Place and Performance. New York: Berghan Books.

Donaire, J.A.; Camprubí, R. \& Galí, N.

2014. Tourist clusters from Flickr travel photography. Tourism Management Perspectives, 11, 26-33.

Faiguenbaum, S.

2011. Definiciones oficiales de "rural" y/o "urbano" en el mundo. En CEPAL, Hacia una nueva definición de "rural" con fines estadísticos en América Latina. Santiago de Chile: CEPAL.

Galí, N. y Donaire, J.A.

2015. Tourists taking photographs: the long tail in tourists' perceived image of Barcelona. Current Issues in Tourism, 18 (9): 893-902.

Garrod, B.

2008. Exploring place perception. A photo-based analysis. Annals of Tourism Research, 35, 2, 381-401.

Hall, C. M. y Page, S.J.

2014. The geography of tourism and recreation: Environment, place and space. Abingdon: Routledge.

Hall, C.M. y Valentin, A.

2005. Content Analysis. En Ritchie, B.W.; Burns, P. y Palmer, C. Tourism Research Methods: Integrating Theory with Practice. (pp.191-2010). Cambridge: CABI publishing.

Hochman, N. y Manovich, L.

2013. Zooming into an Instagram City: Reading the local through social media. First mond@y http:// firstmonday.org/article/view/4711/3698 (consultado el 27/08/2016)

Holsti, O.R.

1968. Content Analysis. En Lindzey, G. y Aronson E. (Eds.) The handbook of Social Psychology 2. Reading MA: Addison-Wesley. 596692.

Hunter, W.C.

2016. The social construction of tourism online destination image: A comparative semiotic analysis of the visual representation of Seoul. Tourism Management, 54: 221-229.

Katsoni, V.

2014. The strategic role of virtual communities and social network sites on tourism destination marketing. e-Journal of Science \& Technology, 5, 9, 107-117. http://e-jst.teiath.gr/triantatessera_teuxos.htm (consultado el 13/03/2017).

Mackay, K.J. y Couldwell, C.M.

2004. Using visitor-employed photography to investigate destination image. Journal of Travel Research, 42 (4): 390-396.

Martínez, E.J.

2013. Localidades de menos de 5000 habitantes en el Uruguay. Montevideo: Instituto de Teoría de la Arquitectura y Urbanismo - UDELAR.

Massey, D.

2001. Talking of space-time. Transactions of the institute of British Geographers, 26 (2): 257-261.

Miossec, J.-M.

1977. L’image touristique comme introduction à la géographie du tourisme. Annales de Géographie, 86 (473): 55-70.

Monreal, M.

2012. Uruguay. Madrid: GAESA.

Nielsen, K., Hausner, J., \& Jessop, B.

1995. Institutional change in post-structuralism. En Hausner, I, Jessop, B y Nielsen, K (Eds.) Strategic

Choice and Path Dependency in Post-structuralism Aldershot: Edward Elgar Publishing, Incorporated. 3-44.

Pagella, G.

2013. Uruguay: Montevideo, Salto, Punta del Este y más. Madrid: Anaya Touring.

Pan, B., y Li, X.

2011. The long tail of destination image and online marketing. Annals of Tourism Research, 38 (1): 132-152. 
Paül i Agustí, D. 2014. Differences in the location of urban museums and their impact on urban areas. International Journal of Cultural Policy, 20 (4): 471-495.

Paül i Agustí, D. 2016. Agricultura, muntanyes i... La percepció de la província de Lleida per part dels estudiants universitaris catalans. Documents d'Anàlisi Geogràfica, 62 (1): 111-132.

Piñeiro, D.E. y Cardeillac, J.

2014. Población rural en Uruguay Aportes para su reconceptualización. Revista de Ciencias Sociales, 27 (34): 53-70.

Pritchard, A y Morgan, N.

1995. Evaluating vacation destination brochure images: the case of local authorities in Wales. Journal of Vacation Marketing, 2 (1): 23-38.

Serrano i Miracle, D.; Imbert-Bouchard Ribera, D.

2009. Anàlisi de mercat: la Catalunya que es ven a les principals guies turístiques. En López Palomeque, F. (dir.) Atles del turisme a Catalunya. Barcelona: Generalitat de Catalunya. 389-405.

Sosa, V.

2016. Anuario 2016 Estadísticas de Turismo. Montevideo: Ministerio de Turismo.

Stylianou-Lamber, T.

2012. Tourists with Cameras. Reproducing or Producing?. Annals of Tourism Research, 39 (4): 1817-1838.

Tigre Moura, F., Gnoth, J., \& Deans, K. R.

2015. Localizing cultural values on tourism destination websites: The effects on users' willingness to travel and destination image. Journal of Travel Research, 54 (4): 528-542.

Urry, J.

199). The tourist gaze. London: Sage.

Vienne, F.; Douay, N.; Le Goix, R. \& Severo, M.

2017. Les territoires du réseau social facebook : le cas des pratiques de géoréférencements. Territoire en mouvement Revue de géographie et aménagement 34

Zhou, L.

2014. Online rural destination images: Tourism and rurality. Journal of Destination Marketing \& Management, 3 (4): 227-240.

\section{Notas}

https://data.worldbank.org/indicator/SP.URB.TOTL.IN.ZS 